\title{
Teaching efficacy of U.S. Air Force enlisted professional military educators during the COVID-19 pandemic
}

DOI 10.2478/jms-2021-0002

Received: November 18, 2020; Accepted: February 04, 2021

\begin{abstract}
Due to the COVID-19 pandemic, U.S. Air Force Enlisted Professional Military Education (EPME) was forced to deliver traditionally in-person leadership development interventions in an online, instructor-facilitated format for the first time in the history of the programme. Despite the absence of training to teach in online learning environments, hundreds of instructors within 80 schoolhouses were charged with embracing this pedagogic shift to continue developing enlisted leaders during a global pandemic. This study examined the sense of self-efficacy of 129 instructors across all levels of U.S. Air Force EPME by utilising a 32-item self-efficacy measurement instrument. This study has implications for enlisted and officer professional military education leaders interested in training and developing faculty to teach in online learning environments. Overall, instructors felt confident in their abilities to teach online, despite pre-service training having focussed solely on in-person instruction. Results indicated a positive relationship between higher senses of self-efficacy and years of instructors' experience. Instructors who worked with an instructional support specialist showed a significantly higher sense of self-efficacy than instructors who did not. Future studies should aim to integrate multiple perspectives of the efficacy of U.S. Air Force EPME instructors, such as those from students, administrators and colleagues.
\end{abstract}

Keywords: PME, EPME, Air Force, Teacher Efficacy

\section{Introduction}

In Spring 2020, the COVID-19 pandemic forced schools and universities across the U.S. to shift traditionally in-person

*Corresponding author: Jason Keys, Education Directorate Superintendent; Air University, 50 S Turner Blvd, Montgomery, AL 36114; E-mail: jason.keys.1@us.af.mil instruction to online learning environments, and U.S. Air Force Enlisted Professional Military Education (EPME) was not spared from this mandated change in pedagogic practice (Culbert 2020). Hundreds of instructors teaching leadership development interventions at multiple levels of professional military education found themselves forced to teach online for the first time in the history of EPME (Culbert 2020).

In-residence and facilitated online EPME courses were similar in that students attended both for the same length of time, completed the same classroom discussions and assessments which were postured towards similar learning outcomes and received the same number of college credits for attendance (Smith 2020). However, online EPME delivery lacked tactile games and activities that were used to reinforce lesson concepts within the in-residence course, and mandated mastery of videoconferencing and online collaboration tools that are not used during in-person instruction, requiring instructors to quickly develop alternate delivery methods of classroom material (Kingery 2020). This study aimed to examine the interrelationship between teachers' self-efficacy and the associated shift in pedagogic practice.

U.S. Air Force guidance stated, “...distance learning instructors must complete the same qualification process as a traditional class room instructor" (Community College of the Air Force [CCAF] 2017, p. 25) and did not mandate pre-service or in-service training specific to teaching in online learning environments. Given the fact that no data has ever been collected on the efficacy of U.S. Air Force EPME instructors teaching online, this study examined the reported teachers' self-efficacy levels of instructors after they had begun to teach in online environments. The results of this study can be used to better inform enlisted and officer professional military education decisionmakers across the Department of Defense (DOD) on where to surgically allocate faculty development resources for online instructors. 


\section{Background and literature review}

\subsection{Online EPME as a necessity}

U.S. Air Force EPME prepares Airmen for leadership roles as they increase in both rank and responsibility (O'Neil 2020; Rivera \& Shufelt 2016). Students are noncommissioned officers serving in roles which range from immediate supervisors to leaders responsible for managing, inspiring and motivating thousands of Airmen worldwide (O’Neil 2020; Bangari 2014; Rivera \& Shufelt 2016). Air Force EPME consists of four levels of training, with Airmen attending each course as they advance in rank (AF/A1D 2018). There are over 500 instructors teaching the various levels of EPME across 80 schools globally (Thomas N. Barnes Center for Enlisted Education 2020a, 2020b, 2020c).

Tens of thousands of Airmen who are annually selected for promotion require EPME completion before assuming the next rank (AF/A1D 2018). Therefore, there was a need to continue courses during the CoViD-19 pandemic. Due to the necessity of continued EPME, resistance to change was not an option, and EPME instructors and schoolhouses were forced to adopt online delivery methods for courses that had traditionally been taught in face-to-face environments (Culbert 2020). Air Force guidance stated that “...distance learning instructors must complete the same qualification process as a traditional class room instructor" (CCAF 2017, p. 25) and did not mandate pre-service or in-service training specific to teaching online. Therefore, this study aimed to glean insight into the perceived selfefficacy of U.S. Air Force EPME instructors to better inform future decisions regarding training and development for online faculty.

\subsection{Synchronous and asynchronous online teaching and learning}

Rapid technological developments have enabled the rise of effective and efficient online learning systems (Dhawan 2020). Online learning uses computer networks to allow for the possibility for students and teachers to use computers and internet-connections to interact anywhere, anytime and in a rhythm and manner which is most beneficial to learning (Cojocariu et al. 2014). Synchronous online learning allows the learning environment to mimic in-person instruction with live lectures, discussions and interactions between students and teachers, whereas in asynchronous environments, learning can occur in different times and spaces that are particular to each learner (Guo 2020; Dhawan 2020). During the COVID-19 pandemic, U.S. Air Force EPME leveraged both delivery methods (Culbert 2020).

\subsection{Teachers' self-efficacy}

Bernhardt (2018) noted that there are different varieties of data which one can analyse to examine the efficacy of learning environments such as student learning data (e.g. success in reaching learning outcomes), process data (e.g. cost, organisational processes) and demographic data (e.g. attendance, graduation rates). This study examined teachers' self-efficacy by obtaining perceptions data directly from faculty members, since perceptions data is ideal for analysing thoughts, feelings and opinions of participants (Bernhardt 2018).

While Bandura (1977) defined the concept of selfefficacy as an individual's belief that they are capable of executing specific performance attainments, teachers' self-efficacy refers to the self-efficacy of professional educators, and can be defined as the belief in one's abilities to "plan, organise, and carry out activities required to attain given educational goals" (Skaalvik \& Skaalvik 2007, p. 612). Tschannen-Moran et al. (1998), in their comprehensive literature review, noted that higher senses of teachers' self-efficacy bring forth feelings of perseverance, curiosity and drive to continuously improve pedagogic practices. Bandura (1977) noted that teachers with high levels of self-efficacy could maintain a positive outlook and succeed in situations where they feel unprepared or uncomfortable.

Teachers' self-efficacy impacts teachers, students and schools (Stephanou et al. 2013). Skaalvik and Skaalvik (2019) noted a correlation between higher senses of self-efficacy and increased levels of student engagement. Zhang and Liu (2019) explained that teachers' sense of self-efficacy plays a moderating role when examining motivational regulation, perceived task value and learner engagement, with the moderating effect increasing as the teachers' sense of self-efficacy increases. Teachers' self-efficacy has been examined from a myriad of angles, such as the difference in efficacy between male and female college professors (Chang et al. 2011), the difference in efficacy based on years of experience (Mehdinezhad 2012) and the difference in perceived self-efficacy of online teachers based on the age, education level, gender and number of classes taught online (Robinia and Anderson 2010).

Built upon foundational practices from eight previous methods used to measure teachers' efficacy, 
Tschannen-Moran and Hoy (2001) crafted and validated an instrument known as the Ohio State teacher efficacy scale (OSTES), measuring the teachers' sense of efficacy of $\mathrm{K}-12$ educators. A factor analysis using pre-service teachers' responses to the 24 items on the instrument identified three main factors: efficacy in instructional strategies (8 items; alpha $=0.91$ ), efficacy in student engagement (8 items; alpha $=0.87$ ), efficacy for classroom management ( 8 items; alpha $=0.90)$ and an overall combined OSTSES score (24 items; alpha $=0.94$ ).

The OSTES was further refined and validated when Robinia and Anderson (2010) modified the instrument (with permission) for use by nursing educators teaching online at the collegiate level. In addition to examining the three dimensions of teachers' sense of efficacy within the OSTES, this revised instrument, known as the Michigan Nurse Educators Sense of Efficacy for Online Teaching (MNESEOT; see Appendix), brought the OSTES into the digital age by incorporating and examining an additional fourth dimension of teachers' self-efficacy: computer use. The researchers validated the 32-item instrument by conducting a factor analysis, resulting in four factors: efficacy in online student engagement (0.93), efficacy in online instructional strategies (0.94), efficacy for online classroom management (0.93) and efficacy in the use of computers (0.86). A total score for the entire instrument (0.93) was also derived.

Robinia and Anderson (2010) administered the MNESEOT to 327 participants, receiving a $43 \%$ usable response rate, or 140 participants, from college-level nursing educators across the state of Michigan. Results indicated a positive and significant correlation between teachers who had met with an instructional support expert (such as an expert in educational technology or online delivery methods) and sense of teaching selfefficacy, as well as a positive and significant correlation between educators who had taken a course in online teaching and sense of teaching self-efficacy. Robinia and Anderson (2010) also noted a positive and significant correlation between the number of online teaching experiences and higher senses of teachers' self-efficacy. Participants felt higher senses of teachers' self-efficacy in the subscales of classroom management and instructional strategies, whereas student engagement was noted as the category where educators felt least confident when teaching online.

Horvitz et al. (2014) used a modified web-based MNESEOT instrument to ascertain the sense of efficacy of 91 college-level educators within a variety of organisations specialising in liberal arts and humanities, STEM and professional skills development. Results mirrored those of
Robinia and Anderson (2010): the highest efficacy scores were observed in the instructional strategies and classroom management categories, whereas the lowest efficacy scores were observed in the student engagement category. Results indicated that there was a significant and positive correlation between the number of semesters taught online and the teachers' sense of self-efficacy, indicating that as an educator has more experience teaching online, their sense of efficacy rises. Unique to the study was data indicating that educators affiliated with professional schools, as opposed to traditional colleges, displayed a significantly higher sense of efficacy in the subscale of computer use.

Aside from the MNESEOT, other instruments have been used to measure teachers' sense of efficacy. Chang et al. (2011) examined the teachers' self-efficacy of 513 university-level educators in Taiwan using the Faculty Teaching Efficacy Questionnaire, an instrument comprised of 28 four-point-Likert items. The items were affiliated with six factors: efficacy for course design, technology usage, instructional strategy, class management, interpersonal relation and learning assessment. Factor analysis results for each factor were consistently large, between 0.58 and 0.88 . $73.59 \%$ of the total variance was accounted for by all six factors. The categories of internal consistency reliability for course design, instructional strategy, technology usage, class management, interpersonal relation, learning assessment and the total scale were $0.91,0.88,0.93,0.90,0.86,0.87$ and 0.95, respectively (Chang et al. 2011). Results indicated that educators' sense of teaching efficacy was lower for teachers with five or fewer years of experience than their counterparts who had taught for 6 years or longer. Results also indicated that institutional investment in educators' professional development, such as assigning coaches, mentors or specialists to hone the skill-sets of educators, positively correlated with teachers' sense of self-efficacy.

Although teachers' self-efficacy has been thoroughly studied within K-12 and postsecondary education (Norton 2013; Walsh et al. 2020; Avalos 2011; Loughland and Nguyen 2020), it is true that less is known about the self-efficacy of U.S. Air Force EPME instructors teaching leadership interventions at the collegiate level. This study aimed to continue the work of Robinia and Anderson (2010) by utilising their self-efficacy measurement instrument (with permission) to examine the variables that affect the self-efficacy of EPME instructors who were forced to teach online during the COVID-19 pandemic without specialised training to instruct in online learning environments. 


\subsection{Research questions}

Online EPME instructors were not required to be trained to teach in ways specific to online learning environments (CCAF 2017). With hundreds of instructors teaching online with no formalised training specific to online instruction, this study began with the following research questions:

1. How confident do EPME instructors feel in preparing, conducting and evaluating online courses? Is there a difference in online teaching efficacy in relation to the variables: (a) military rank, (b) years of teaching EPME, (c) number of online classes taught, (d) level of EPME at which the instructor is teaching, (e) instructor education level and (f) the qualification level of the instructor?

2. In what ways do professional development, experience with online teaching and perceived support from colleagues or instructional support specialists influence EPME instructors' reported self-efficacy when teaching online?

\subsection{Hypotheses}

This study examined instructors who were not formally trained to utilise online instructional technologies. As Robinia and Anderson's (2010) results indicated a positive relationship between the number of online teaching experiences and increased self-efficacy levels for online teaching, as well as a positive relationship between working with instructional experts and increased self-efficacy, the hypotheses for this study were as follows:

1. Of the four dimensions of self-efficacy which were examined, the dimension of technology use will be the lowest amongst EPME instructors.

2. There will be a positive relationship between the number of online teaching experiences and increased self-efficacy levels for online teaching.

3. EPME instructors who report experiences of working with instructional support specialists will have significantly higher levels of online teaching efficacy.

\section{Methods}

An online survey was distributed to EPME schoolhouses in September 2020 using a cross-sectional design to examine the sense of self-efficacy of instructors across all four levels of EPME. Instructors were asked to participate if they were currently teaching or had previously taught
Tab. 1: Participants by rank/grade

\begin{tabular}{lrr}
\hline Rank & $\boldsymbol{n}$ & \multicolumn{1}{c}{$\%$} \\
\hline CMSgt/E-9 & 1 & $0.8 \%$ \\
SMSgt/E-8 & 12 & $9.3 \%$ \\
MSgt/E-7 & 33 & $25.6 \%$ \\
TSgt/E-6 & 57 & $44.2 \%$ \\
SSgt/E-5 & 26 & $20.2 \%$ \\
\hline
\end{tabular}

Tab. 2: Respondents teaching at each level of EPME

\begin{tabular}{lrr}
\hline EPME level & \multicolumn{1}{c}{$\boldsymbol{n}$} & \multicolumn{1}{c}{$\%$} \\
\hline Airman Leadership School & 75 & $58.1 \%$ \\
Non-commissioned Officer Academy & 49 & $37.9 \%$ \\
Senior Non-commissioned Officer Academy & 4 & $3.1 \%$ \\
Chief Leadership Course & 1 & $0.8 \%$ \\
\hline
\end{tabular}

EPME online during the COVID-19 pandemic. A review of the EPME faculty training database and an examination of the number of schools teaching courses online revealed a population estimate of 500. The useable response rate was $26 \%$ or 129 participants. The typical survey respondent was serving in the non-commissioned officer pay grades of E-5 or E-6 (66\%; see Table 1) and was assigned to the lowest level of U.S. Air Force EPME, Airman Leadership School (58\%; see Table 2), a fully qualified instructor who had completed all on-the-job training requirements (89\%), held an associate's degree as the highest level of education (52\%) and had almost two years of teaching experience $(M=1.7, S D=1)$. This study was granted exempt status from the institutional review board at Air University.

\subsection{Instrument}

The instrument for this study replicated Robinia and Anderson's (2010) sense of efficacy survey. Since they were not tailored to any specific institution or profession, all 32 questions pertaining to the four dimensions of teachers' self-efficacy (classroom management, student engagement, technology use and instructional strategies) used the exact wording from Robinia and Anderson's (2010) instrument. Modifications were only made to demographic questions at the end of the survey, as this study examined military professionals as opposed to nurse educators.

This study was undertaken to provide actionable data to U.S. Air Force decision-makers. Therefore, the question of gender was intentionally omitted from the background questionnaire, because the U.S. Air Force does not 
consider gender in recruitment, hiring, training, evaluation or retention of EPME faculty (Military Assignments Programs Branch 2020). This study viewed the EPME instructor as a gender-neutral position.

Cronbach's alpha for the entire instrument was established as 0.97. Based on a factor analysis of the 32 items in the instrument, four items were derived coinciding with Robinia and Anderson's (2010) four dimensions of teachers' self-efficacy. Subscale Cronbach's alphas were computed for student engagement (0.92), instructional strategies (0.90), classroom management (0.84) and computer skills (0.85).

\subsection{Process for data collection}

These data were collected using an online survey, and all questionnaires were stored and administered by utilising commercial survey software. After obtaining official e-mail addresses for all instructors from EPME headquarters, instructors were contacted through official U.S. Air Force e-mail, which requested their participation. Within the e-mail, a link provided directions and access to the survey. The survey was closed 2 weeks after the initial solicitation for participants.

\subsection{Data analysis}

This study employed descriptive statistics to describe the sample through frequencies and cross tab comparisons to population statistics. Means and standard deviations were calculated to answer questions posed within this research. When determining correlations between interval-level variables, Pearson's product-moment correlation coefficient was used. Analysis of variance was used to test differences between the means of the online teaching efficacy scores. This study used alpha of 0.05 throughout all tests.

\subsection{Factor analysis}

Factor analysis was conducted to ensure items within the questionnaire measured the appropriate category of teachers' self-efficacy. With a sample size of 129 participants, principal axis factor analysis with varimax rotation was conducted to assess the underlying structure of the 32 items of the instrument using SPSS version 27. Four factors were requested, based on the presumption that questions were designed to index four constructs: classroom management, technology use, learner engagement and instructional strategies. After rotation, four components emerged with eigenvalues greater than one, explaining $19 \%, 17 \%, 15 \%$ and $8 \%$ of the variance respectively. As recommended by Morgan et al. (2019), factors less than 0.3 were omitted to improve clarity, since the correlation matrix revealed a majority of coefficients of 0.3 and greater. Used to measure sampling adequacy, results from the Kaiser-Meyer-Olkin test were $>0.70$, exceeding the recommended value of 0.6 (Pallant 2020). Bartlett's test of sphericity produced a value $<0.05$, substantiating factorability of the correlation matrix (Morgan et al. 2019).

Varimax rotation indicated that 11 items loaded strongly on one component consisting of questions related to classroom management. Twelve items loaded strongly on two components consisting mainly of questions related to technology use. Nine items loaded strongly on a third component consisting of questions related to instructional strategies. Questions related to student engagement were represented across all four components.

\section{Results}

\subsection{Efficacy levels of EPME instructors related to online teaching}

The 32-item instrument directed participants to respond to items using a Likert-scale format ranging from nothing (1) to a great deal (9) in relation to questions pertaining to online teaching.

Mean subscale scores within the domains of classroom management, instructional strategies, student engagement and technology use were calculated (Table 3). These scores were then combined to create a total sense of efficacy score, ranging from 4 to 36. Generally, participants indicated they felt they could do more than "some" to "quite a bit" when tasked with preparing, conducting and evaluating online courses. No participant felt they could do "nothing" in any category. The mean score for the instrument was 26.92 with a standard deviation of 5.25 .

Tab. 3: Online teaching efficacy ratings

\begin{tabular}{lccl}
\hline Efficacy dimension & $\boldsymbol{M}$ & SD & Range \\
\hline Student engagement & 6.34 & 1.42 & $2.38-9$ \\
Instructional strategies & 6.67 & 1.32 & $3.38-9$ \\
Classroom management & 7.04 & 1.25 & $3.86-9$ \\
Technology use & 6.89 & 1.26 & $3.0-9$ \\
\hline
\end{tabular}


One-way between-groups analysis of variance showed no significant difference in sense of efficacy scores for rank $[F(4,123)=.957), p=0.434]$, level of EPME $[F(6,122)=1.85), p=0.95]$, instructor's education level $[F(2,126)=1.09), p=0.34]$ or number of online courses taught $[F(5,121)=1.73) p=0.13]$.

An independent samples $t$-test found no significant difference between instructor trainees $(n=9, M=7$, $S D=0.76)$ and fully qualified instructors $(n=116, M=6.69$, $S D=1.26), t(123)=.713, p=0.48$, or respondents who had a degree in education $(n=19, M=6.57, S D=1.24)$ and respondents without a degree in education $(n=107$, $M=6.71, S D=1.22), t(124)=-0.465, p=0.64$.

One-way between-groups analysis of variance showed a significant difference in sense of efficacy scores based on number of years having taught EPME $[F(3,124)=4.148$ ), $p=0.008$ ]. Responses regarding years of teaching EPME were further categorised as (a) less than one year, (b) between 1 and 2 years, (c) between 2 and 3 years and (d) three or more years, as there was noted a rise or fall of sense of teachers' self-efficacy at each of those points (see Figure 1). The effect size was medium to large at 0.09 according to Cohen (2013). Post hoc comparisons using the Tukey's honestly significant difference test indicated that a significant difference was found between instructors who had taught between 1 and 2 years and instructors who had taught between 2 and 3 years $(p=<0.05)$.

\subsection{Preparatory experiences for online EPME instructors}

Participants were asked to identify whether they had any of five possible preparatory experiences for online teaching including: (a) having a teaching degree, (b) taking a seminar on online teaching, (c) taking a course on online teaching, (d) meeting with a peer mentor on a regular basis during an online teaching experience and (e) meeting with an instructional support expert during an online teaching experience. Affirmative responses were directed to additional questions which asked participants to rate their agreement that the experience prepared them in the skills necessary to teach online. A Likert-type scale was used with ratings of $1=$ strongly disagree, 2 = slightly disagree, $3=$ neutral, $4=$ agree and $5=$ strongly agree.

An independent sample $t$-test found significant differences in total sense of efficacy scores for instructors who had met with an instructional support expert during an online teaching experience $(\mathrm{M}=7.09, \mathrm{SD}=1.07) \mathrm{com}$ pared to instructors who did not $(\mathrm{M}=6.56, \mathrm{SD}=1.21)$ $t(122)=-2.02, p=0.04$. Pearson's product-moment coefficient revealed positive and significant correlations between both meeting with an instructional support expert during an online teaching experience and overall sense of efficacy, with a medium or typical effect size (0.47) according to Cohen (2013).

Independent samples $t$-tests found no significant differences in the efficacy levels between instructors who had a teaching degree $(M=6.57, S D=1.24)$ and those who did not have a teaching degree $(M=6.71, S D=1.21)$, $t(124)=-0.465, p=0.66$, those who had taken a course on online teaching $(\mathrm{M}=6.57, \mathrm{SD}=1.30)$ and those who had not $(M=6.74, S D=1.19), t(124)=-0.672, p=0.5$, those who had attended a seminar on online teaching $(M=6.7$, $\mathrm{SD}=1.30)$ and those who had not $(\mathrm{M}=6.7, \mathrm{SD}=1.19)$, $t(124)=0.032, p=0.97$ or those who had met with peer mentors on a regular basis during an online teaching experience $(M=6.83, S D=1.11)$ and those who had not $(\mathrm{M}=6.57, \mathrm{SD}=1.29), t(124)=1.18, p=0.24$.

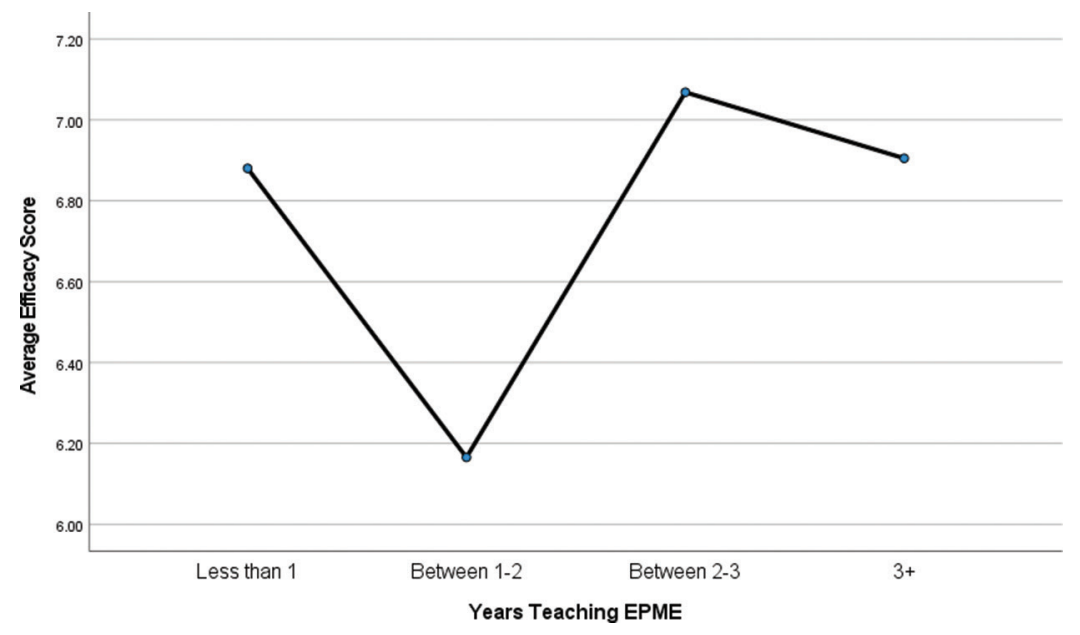

Fig. 1: Efficacy of EPME instructors based on years of experience. 


\subsection{Hypothesis findings}

Hypothesis 1 was not supported, as the self-efficacy dimension of technology use was not the lowest reported among EPME instructors. Hypothesis 2 was also not supported, as there was no positive relationship between the number of online teaching experiences and increased self-efficacy levels for online teaching. Hypothesis 3 was supported, as EPME instructors who reported working with instructional support specialists also reported significantly higher levels of online teaching efficacy.

\section{Discussion}

Results from this study of 129 U.S. Air Force EPME instructors indicate that they are relatively confident in their abilities to prepare for, conduct and evaluate online courses. Across all ranks and EPME levels, instructors expressed that they felt they could do between "some" and "quite a bit" across the four dimensions of teachers' self-efficacy when teaching online. This is the same range of confidence levels reported by Robinia and Anderson (2010). These data indicate that pre-service and in-service faculty development efforts, which do not focus on online teaching strategies, are sufficient for developing faculty to teach online.

Results confirm that there is no significant difference in perceived levels of teachers' self-efficacy between military ranks, levels of EPME at which instructors teach, education levels of instructors or instructors who have completed and not completed all instructor qualification training requirements. Therefore, when managing talent within EPME, DOD leaders should consider that instructors across the above-mentioned categories feel equally confident and competent in their abilities to accomplish tasks and meet goals. Talent management decisions could potentially be made without regard to rank, level at which an instructor is teaching or the instructor's education level, instead focussing on overall experience in the EPME enterprise.

Analysis indicates there is a significant positive correlation between the amount of time an instructor has been teaching and their sense of self-efficacy when teaching online courses, which results are similar to those revealed by Horvitz et al. (2014) and Robinia and Anderson (2010). Results reveal that instructors with minimal experience feel relatively high levels of confidence, with that confidence decreasing over the first year of teaching before rising once more as experienced is gained. This drop and subsequent rise in teachers' sense of efficacy has been noted by Tollerud (1990) and Tschannen-Moran et al. (1998). Chang et al. (2011) Horvitz et al. (2014) and Robinia and Anderson (2010) noted that teachers with higher senses of self-efficacy are more confident, display more agility and better engage with students in online learning environments. Thus, DOD professional military education leadership should consider choosing more seasoned instructors to teach online, since they would potentially have higher senses of self-efficacy and create more engaging and effective online learning environments.

This study also highlighted the importance of preparatory experiences for online instructors, showing a positive significant correlation between higher efficacy scores and instructors who had collaborated with instructional support specialists when teaching online. Instructional support specialists provide coaching and mentorship to teachers, model effective teaching strategies and can specialise in areas such as educational psychology or educational technology (Lee 2001). These results coincide with prior studies on online instruction, which reiterated the need for external support to facilitate online instruction (Johnson 2008; Kim \& Bonk 2006; Maguire 2005, Robinia \& Anderson 2010). DOD professional military education leadership who wish to increase the measure of efficacy of online instructors should consider integrating instructional support specialists into faculty training and development efforts.

Student engagement was the efficacy sub-category where instructors felt the least confident and competent when teaching online, similar to the findings of Robinia and Anderson (2010) and Horvitz et al. (2014). While pre-service and in-service instructor training appears to sufficiently prepare instructors to teach online, future modifications to training should focus on student engagement techniques within online learning environments.

\section{Limitations}

This study relied solely on perceptions data. Perceptions data refer to data which have been collected to examine peoples' beliefs, sentiments and feelings about an educational experience (Bernhardt 2018). To gain a more holistic understanding of the efficacy of EPME instructors teaching online, future studies should incorporate the remaining three facets of data-driven decision-making as per Bernhardt (2018): student learning data (e.g. success in reaching learning outcomes), process data (e.g. cost, 
organisational processes) and demographic data (e.g. attendance, graduation rates).

Additionally, this study only collected perceptions data from EPME instructors. Future studies on EPME instructor efficacy should triangulate perceptions data from multiple data sources to include students, administrators and EPME leadership teams. This would allow participation from a broader number of participants than would otherwise be allowed to participate, since disparate viewpoints of the same instructor are used to strengthen the validity of findings (Carter et al. 2014).

During this study, the Airman Leadership School level of EPME delivered the same curriculum as they had previously taught in-residence for the preceding 12 months, while the Non-Commissioned and Senior NonCommissioned Officer Academy schoolhouses fielded new curricula in conjunction with their shift to online teaching and learning and participated in this study after teaching two courses lasting 25 days each (Smith 2020; Stephens 2020). Future studies should examine the efficacy of the Non-Commissioned and Senior Non-Commissioned Officer Academy instructors after they have become more familiar and comfortable with course content, since the lack of familiarity with the curriculum could have affected the instructors' sense of teachers' self-efficacy.

\section{References}

AF/A1D. (2018). The Enlisted Force Structure (AFH 36-2618). Department of the Air Force. Available at: https://www.afrc. af.mil/Portals/87/documents/PDC/afh36-2618.pdf?ver=202003-10-102348-690

Avalos, B. (2011). Teacher professional development in teaching and teacher education over ten years. Teaching and Teacher Education, 27(1), pp. 10-20. doi: 10.1016/j.tate.2010.08.007.

Bandura, A. (1977). Self-efficacy: Toward a unifying theory of behavioral change. Psychological Review, 84(2), p. 191. doi: 10.1037/0033-295X.84.2.191

Bangari, R. S. (2014). Establishing a framework of transformational grassroots military leadership: Lessons from high-intensity, high-risk operational environments. Vikalpa, 39(3), pp. 13-34. doi: $10.1177 / 0256090920140302$.

Bernhardt, V. L. (2018). Data Analysis for Continuous School Improvement, 4th edn. Routledge, New York, NY.

Carter, N., Bryant-Lukosius, D., DiCenso, A., Blythe, J., \& Neville, A. J. (2014). The use of triangulation in qualitative research. Oncology Nursing Forum, 41(5), pp. 545-547. doi: 10.1188/14. ONF.545-547.

Chang, T. S., Lin, H. H., \& Song, M. M. (2011). University faculty members' perceptions of their teaching efficacy. Innovations in Education and Teaching International, 48, pp. 49-60. https:// doi.org/10.1080/14703297.2010.543770
Cohen, J. (2013). Statistical Power Analysis for the Behavioral Sciences. Academic Press, New York, NY.

Cojocariu, V.-M., Lazar, I., Nedeff, V., \& Lazar, G. (2014). SWOT analysis of e-learning educational services from the perspective of their beneficiaries. Procedia-Social and Behavioral Sciences, 116, pp. 1999-2003. doi: 10.1016/j. sbspro.2014.01.510

Community College of the Air Force. (2017). Policies, procedures, and guidelines. Air University Press, Montgomery, AL.

Culbert, A. (2020, June 15). Class is Back in Session for Barnes Center. Air University Public Affairs. Available at: https://www. airuniversity.af.edu/News/Display/Article/2219965/class-isback-in-session-for-barnes-center/ [retrieved 1 November, 2020].

Dhawan, S. (2020). Online learning: A panacea in the time of COVID-19 crisis. Journal of Educational Technology Systems, 49(1), pp. 5-22. doi: 10.1177/0047239520934018.

Guo, S. (2020). Synchronous versus asynchronous online teaching of physics during the COVID-19 pandemic. Physics Education, 55(6), p. 065007. doi: 10.1088/1361-6552/aba1c5.

Horvitz, B. S., Beach, A. L., Anderson, M. L., \& Xia, J. (2014). Examination of faculty self-efficacy related to online teaching. Innovative Higher Education, 40(4), pp. 305-316. doi: 10.1007/ s10755-014-9316-1.

Johnson, A. E. (2008). A nursing faculty's transition to teaching online. Nursing Education Perspectives, 29, pp. 17-22. PMID: 18330417

Kim, K. J., \& Bonk, C. J. (2006). The future of online teaching and learning in higher education: The survey says.... Educause Quarterly, November, 4, pp. 22-30. Available at: https://cyber. harvard.edu/communia2010/sites/communia2010/images/ Kim_Bonk_2006_Future_of_Online_Teaching_and_Learning_ in_Higher_Education.pdf [retrieved 15 November, 2020].

Kingery, R. (2020). Barnes Center Graduates First Virtual Calss. Available at: https://www.af.mil/News/Article-Display/ Article/2188088/barnes-center-graduates-first-virtual-class/ [retrieved 1 November, 2020].

Lee, J. (2001). Instructional support for distance education and faculty motivation, commitment, satisfaction. British Journal of Educational Technology, 32(2), pp. 153-160. doi: 10.1111/14678535.00186.

Loughland, T., \& Nguyen, H. T. (2020). Using teacher collective efficacy as a conceptual framework for teacher professional learning - A case study. Australian Journal of Education, 64(2), pp. 147-160. doi: 10.1177/0004944120908968.

Maguire, L. L. (2005). Literature review - Faculty participation in online distance education: Barriers and motivators. Online Journal of Distance Learning Administration, 8. Available at: https://www.westga.edu/ distance/ojdla/spring81/ maguire81.pdf [retrieved 18 November, 2020].

Mehdinezhad, V. (2012). Relationship between high school teachers' wellbeing and teachers' efficacy. Acta Scientiarum. Education, 34(2), pp. 233-241 doi: 10.4025/actascieduc.v34i2.16716.

Military Assignments Programs Branch. (2020, June 5). Special Duty Catalog. Department of the Air Force, Randolph Air Force Base, Texas.

Morgan, G. A., Barrett, K. C., Leech, N. L., \& Gloeckner, G. W. (2019). IBM SPSS for Introductory Statistics: Use and Interpretation. Routledge, New York, NY. 
Norton, S. M. (2013). A phenomenological investigation into the self-efficacy beliefs of teachers who have persisted in the teaching profession (Doctoral dissertation). Retrieved from ProQuest.(3591045).

O'Neil, B. D. (2020). Servant Leadership Curriculum in Professional Military Education: A Qualitative Study (Order No. 27831692). Available from ProQuest Dissertations \& Theses A\&I. (2390145528). Retrieved from https://search-proquest-com.ulm.idm.oclc.org/ docview $/ 2390145528$ ? accountid $=26268$

Pallant, J. (2020). SPSS Survival Manual: A Step by Step Guide to Data Analysis Using IBM SPSS. Routledge, London.

Rivera, L., \& Shufelt, J. (2016). Developing strategic thinking in the NCO Corps of 2025. US Army War College. Available at: https:// publications.armywarcollege.edu/pubs/925.pdf [retrieved 1 October, 2020].

Robinia, K. A., \& Anderson, M. L. (2010). Online teaching efficacy of nurse faculty. Journal of Professional Nursing, 26, pp. 168-175. doi: 10.1016/j.profnurs.2010.02.006.

Skaalvik, E. M., \& Skaalvik, S. (2019). Teacher self-efficacy and collective teacher efficacy: relations with perceived job resources and job demands, feeling of belonging, and teacher engagement. Creative Education, 10(7), pp. 1400-1424. doi: 10.4236/ce.2019.107104.

Skaalvik, E., \& Skaalvik, S. (2007). Dimensions of teacher self-efficacy and relation with strain factors, perceived collective teacher self-efficacy, and teacher burnout. Journal of Educational Psychology, 99(3), pp. 611-625. doi: 10.1037/00220663.99.3.611.

Smith, M. (2020, June 17). FAQs for virtual in-resident remote EPME courses. Available at: https://www.ang.af.mil/Media/ Article-Display/Article/2222671/faqs-for-virtual-in-resident-remote-epme-courses/ [retrieved 1 February, 2021].

Stephanou, G., Gkavras, G., \& Doulkeridou, M. (2013). The role of teachers' self-and collective-efficacy beliefs on their job satisfaction and experienced emotions in school. Psychology, 4(3), p. 268. Available at: https://www.scirp.org/html/29237. html [retrieved 22 October, 2020].
Stephens, J. (2020). Taking a virtual approach to ALS. Available at: https://www.dm.af.mil/Media/Article-View/Article/2193662/ taking-a-virtual-approach-to-als/ [retrieved 10 December, 2020].

Thomas, N., Barnes Center for Enlisted Education. (2020a, May 6). Airman Leadership School (ALS). Air University. Available at: https://www.airuniversity.af.edu/Barnes/Airman-Leadership-School/ [retrieved 2 November, 2020].

Thomas, N., Barnes Center for Enlisted Education. (2020b, May 6). Thomas N. Barnes Center for Enlisted Education. Air University. Available at: https://www.airuniversity.af.edu/Barnes/ [retrieved 2 November, 2020].

Thomas, N., Barnes Center for Enlisted Education. (2020c, October 1). Noncommissioned Officer Academy (NCOA). Air University. Available at: https://www.airuniversity.af.edu/ Barnes/NCO-Academy/ [retrieved 2 November, 2020].

Tollerud, T. (1990). The perceived self efficacy of teaching skills of advanced doctoral students and graduates from counselor education programs (Dissertation Abstracts International, 51: 12A). University of lowa, lowa City.

Tschannen-Moran, M., Hoy, A. W., \& Hoy, W. K. (1998). Teacher efficacy: Its meaning and measure. Review of educational research, 68(2), pp. 202-248. doi: 10.3102/00346543068002202.

Tschannen-Moran, M., \& Hoy, A. W. (2001). Teacher efficacy: Capturing an elusive construct. Teaching and Teacher Education, 17, pp. 783-805. doi: 10.1016/ S0742-051X(01)00036-1.

Walsh, N. R., Ginger, K., \& Akhavan, N. (2020). Benefits of instructional coaching for teacher efficacy: A mixed methods study with PreK-6 teachers in California. Issues in Educational Research, 30(3), pp. 1143-1161. Available at: http://www.iier.org.au/iier30/walsh.pdf [retrieved 15 November, 2020].

Zhang, S., \& Liu, Q. (2019). Investigating the relationships among teachers' motivational beliefs, motivational regulation, and their learning engagement in online professional learning communities. Computers \& Education, 134, pp. 145-155. doi: 10.1016/j.compedu.2019.02.013. 


\section{Appendix}

Michigan Nurse Educators Sense of Efficacy for Online Teaching Scale

Example Revised from: Teachers’ Sense of Efficacy Teaching Scale (Tschannen-Moran and Hoy; 2001)

Directions: You are invited to participate in this study because the institution at which you are employed has you on record as teaching a theoretical course this winter/spring 2008 semester. You meet the parameters of the sample set for this study if you are indeed teaching a face-to-face and/or an online theory course. This questionnaire is designed to help us gain a better understanding of the current self-perceptions nurse educators hold regarding their abilities to successfully teach in online environments. Perceptions are sought from educators with little or no online teaching experience and educators having some or extensive online teaching experience. Please indicate your opinion about each of the statements below. Your answers are confidential.

Questions 1-32 are concerned with understanding how nurse educators judge their current capabilities for teaching online nursing lecture courses. Even if you have little or no experience with online teaching, please try to answer each question. A helpful prefix to each answer is, "I can do...."

1. How much can you do to help your students think critically in an online class?

\begin{tabular}{lcccccccc} 
Nothing & \multicolumn{3}{c}{ Very Little } & Some & & Quite a Bit & A Great Deal \\
\hline $\mathbf{1}$ & 2 & 3 & 4 & 5 & 6 & 7 & 8 & 9 \\
\hline
\end{tabular}

2. How much can you do to get through to disengaged students in an online class? (e.g. passive learners who might lurk online, but fail to actively contribute to their own learning.)

\begin{tabular}{lcccccccc} 
Nothing & \multicolumn{3}{c}{ Very Little } & Some & & Quite a Bit & A Great Deal \\
\hline 1 & 2 & 3 & 4 & 5 & 6 & 7 & 8 & 9 \\
\hline
\end{tabular}

3. How much can you do to control disruptive behavior (e.g. disrespectful posting or failure to adhere to outline policies for posting) in an online environment?)

\begin{tabular}{llllclccc} 
Nothing & \multicolumn{2}{c}{ Very Little } & Some & & Quite a Bit & A Great Deal \\
\hline 1 & 2 & 3 & 4 & 5 & 6 & 7 & 8 & 9 \\
\hline
\end{tabular}

4. How much can you do to motivate students who show low interest in online work?

\begin{tabular}{lcccccccc} 
Nothing & \multicolumn{2}{c}{ Very Little } & Some & & Quite a Bit & A Great Deal \\
\hline $\mathbf{1}$ & 2 & 3 & 4 & 5 & 6 & 7 & 8 & 9 \\
\hline
\end{tabular}

5. To what extent can you make your expectations clear about student behavior in an online class?

\begin{tabular}{lcccccccc} 
Nothing & \multicolumn{3}{c}{ Very Little } & Some & & Quite a Bit & A Great Deal \\
\hline $\mathbf{1}$ & 2 & 3 & 4 & 5 & 6 & 7 & 8 & 9 \\
\hline
\end{tabular}

6. How much can you do to get students to believe that they can do well in an online class?

\begin{tabular}{lcccccccc} 
Nothing & \multicolumn{3}{c}{ Very Little } & Some & & Quite a Bit & A Great Deal \\
\hline $\mathbf{1}$ & 2 & 3 & 4 & 5 & 6 & 7 & 8 & 9 \\
\hline
\end{tabular}


7. How well can you respond to difficult questions from online students?

\begin{tabular}{lcccccccc} 
Nothing & \multicolumn{2}{c}{ Very Little } & Some & & Quite a Bit & A Great Deal \\
\hline 1 & 2 & 3 & 4 & 5 & 6 & 7 & 8 & 9 \\
\hline
\end{tabular}

8. How well can you establish routines (e.g. facilitate or moderate student participation) in coursework to keep online activities running smoothly?)

\begin{tabular}{lcccccccc} 
Nothing & \multicolumn{2}{c}{ Very Little } & Some & & Quite a Bit & A Great Deal \\
\hline 1 & 2 & 3 & 4 & 5 & 6 & 7 & 8 & 9
\end{tabular}

9. How much can you do to help online students' value learning?

\begin{tabular}{lcccccccc} 
Nothing & \multicolumn{3}{c}{ Very Little } & Some & \multicolumn{3}{c}{ Quite a Bit } & A Great Deal \\
\hline 1 & 2 & 3 & 4 & 5 & 6 & 7 & 8 & 9 \\
\hline
\end{tabular}

10. How much can you gauge student comprehension of what you have taught in an online course?

\begin{tabular}{lcccccccc} 
Nothing & \multicolumn{2}{c}{ Very Little } & Some & \multicolumn{3}{c}{ Quite a Bit } & A Great Deal \\
\hline $\mathbf{1}$ & 2 & 3 & 4 & 5 & 6 & 7 & 8 & 9 \\
\hline
\end{tabular}

11. How well can you craft questions or assignments that require students to think by relating ideas to previous knowledge and experience?

\begin{tabular}{lcccccccc} 
Nothing & \multicolumn{3}{c}{ Very Little } & Some & & Quite a Bit & A Great Deal \\
\hline $\mathbf{1}$ & 2 & 3 & 4 & 5 & 6 & 7 & 8 & 9 \\
\hline
\end{tabular}

12. How much can you do to foster individual student creativity in an online course?

\begin{tabular}{lcccccccc} 
Nothing & \multicolumn{3}{c}{ Very Little } & Some & \multicolumn{3}{c}{ Quite a Bit } & A Great Deal \\
\hline $\mathbf{1}$ & 2 & 3 & 4 & 5 & 6 & 7 & 8 & 9 \\
\hline
\end{tabular}

13. How much can you do to get students to follow the established rules for assignments and deadlines during an online class?

\begin{tabular}{lcccccccc} 
Nothing & \multicolumn{3}{c}{ Very Little } & Some & & Quite a Bit & A Great Deal \\
\hline 1 & 2 & 3 & 4 & 5 & 6 & 7 & 8 & 9 \\
\hline
\end{tabular}

14. How much can you do to improve the understanding of a student who is failing in an online class?

\begin{tabular}{lcccccccc} 
Nothing & \multicolumn{2}{c}{ Very Little } & Some & \multicolumn{3}{c}{ Quite a Bit } & A Great Deal \\
\hline 1 & 2 & 3 & 4 & 5 & 6 & 7 & 8 & 9 \\
\hline
\end{tabular}

15. How much can you do to control students dominating online discussions?

\begin{tabular}{lcccccccc} 
Nothing & \multicolumn{3}{c}{ Very Little } & Some & \multicolumn{3}{c}{ Quite a Bit } & A Great Deal \\
\hline $\mathbf{1}$ & 2 & 3 & 4 & 5 & 6 & 7 & 8 & 9 \\
\hline
\end{tabular}


16. How well can you establish an online course (e.g. convey expectations; standards; course rules) with each group of students?

\begin{tabular}{lcccccccc} 
Nothing & \multicolumn{3}{c}{ Very Little } & Some & & Quite a Bit & A Great Deal \\
\hline 1 & 2 & 3 & 4 & 5 & 6 & 7 & 8 & 9 \\
\hline
\end{tabular}

17. How much can you do to adjust your online lessons for different learning styles?

\begin{tabular}{lcccccccc} 
Nothing & \multicolumn{3}{c}{ Very Little } & Some & & Quite a Bit & A Great Deal \\
\hline 1 & 2 & 3 & 4 & 5 & 6 & 7 & 8 & 9 \\
\hline
\end{tabular}

18. How much can you do to use a variety of assessment strategies for an online course?

\begin{tabular}{lcccccccc} 
Nothing & \multicolumn{2}{c}{ Very Little } & Some & & Quite a Bit & A Great Deal \\
\hline $\mathbf{1}$ & 2 & 3 & 4 & 5 & 6 & 7 & 8 & 9 \\
\hline
\end{tabular}

19. How well can you develop an online course that facilitates student responsibility for online learning?

\begin{tabular}{lcccccccc} 
Nothing & \multicolumn{3}{c}{ Very Little } & Some & & Quite a Bit & A Great Deal \\
\hline $\mathbf{1}$ & 2 & 3 & 4 & 5 & 6 & 7 & 8 & 9 \\
\hline
\end{tabular}

20. To what extent can you provide an alternative explanation or example when students in an online class seem to be confused?

\begin{tabular}{lcccccccc} 
Nothing & \multicolumn{3}{c}{ Very Little } & Some & & Quite a Bit & A Great Deal \\
\hline $\mathbf{1}$ & 2 & 3 & 4 & 5 & 6 & 7 & 8 & 9 \\
\hline
\end{tabular}

21. How well can you respond to defiant students in an online setting?

\begin{tabular}{lcccccccc} 
Nothing & \multicolumn{3}{c}{ Very Little } & Some & & Quite a Bit & A Great Deal \\
\hline $\mathbf{1}$ & 2 & 3 & 4 & 5 & 6 & 7 & 8 & 9 \\
\hline
\end{tabular}

22. How well can you structure an online course that facilitates collaborative learning?

\begin{tabular}{lcccccccc} 
Nothing & \multicolumn{3}{c}{ Very Little } & Some & & Quite a Bit & A Great Deal \\
\hline 1 & 2 & 3 & 4 & 5 & 6 & 7 & 8 & 9 \\
\hline
\end{tabular}

23. How well can you structure an online course that provides good learning experiences for students?

\begin{tabular}{lcccccccc} 
Nothing & \multicolumn{3}{c}{ Very Little } & Some & & Quite a Bit & A Great Deal \\
\hline 1 & 2 & 3 & 4 & 5 & 6 & 7 & 8 & 9 \\
\hline
\end{tabular}

24. How well can you provide appropriate challenges for very capable students in an online environment?

\begin{tabular}{lcccccccc} 
Nothing & \multicolumn{3}{c}{ Very Little } & Some & & Quite a Bit & A Great Deal \\
\hline 1 & 2 & 3 & 4 & 5 & 6 & 7 & 8 & 9 \\
\hline
\end{tabular}


25. To what extent can you use knowledge of copyright law to provide resources for online students?

\begin{tabular}{lcccccccc} 
Nothing & \multicolumn{2}{c}{ Very Little } & Some & \multicolumn{3}{c}{ Quite a Bit } & A Great Deal \\
\hline 1 & 2 & 3 & 4 & 5 & 6 & 7 & 8 & 9 \\
\hline
\end{tabular}

26. How well can you navigate the technical infrastructure at your institution to successfully create an online course?

\begin{tabular}{lcccccccc} 
Nothing & \multicolumn{2}{c}{ Very Little } & Some & & Quite a Bit & A Great Deal \\
\hline 1 & 2 & 3 & 4 & 5 & 6 & 7 & 8 & 9 \\
\hline
\end{tabular}

27. How well can you navigate the technical infrastructure at your institution to successfully teach an established online course?

\begin{tabular}{lcccccccc} 
Nothing & \multicolumn{2}{c}{ Very Little } & Some & & Quite a Bit & A Great Deal \\
\hline $\mathbf{1}$ & 2 & 3 & 4 & 5 & 6 & 7 & 8 & 9 \\
\hline
\end{tabular}

28. To what extent can you use asynchronous discussions to maximise interactions between students in an online course? (Asynchronous means not online at the same time)

\begin{tabular}{lcccccccc} 
Nothing & \multicolumn{3}{c}{ Very Little } & Some & & Quite a Bit & A Great Deal \\
\hline $\mathbf{1}$ & 2 & 3 & 4 & 5 & 6 & 7 & 8 & 9 \\
\hline
\end{tabular}

29. To what extent can you use synchronous discussions (e.g. same time chat rooms) to maximise interaction between students in an online course?

\begin{tabular}{lcccccccc} 
Nothing & \multicolumn{2}{c}{ Very Little } & Some & & Quite a Bit & A Great Deal \\
\hline 1 & 2 & 3 & 4 & 5 & 6 & 7 & 8 & 9 \\
\hline
\end{tabular}

30. How well can you use computers for word processing, internet searching and e-mail communication?

\begin{tabular}{lcccccccc} 
Nothing & \multicolumn{3}{c}{ Very Little } & Some & & Quite a Bit & A Great Deal \\
\hline $\mathbf{1}$ & 2 & 3 & 4 & 5 & 6 & 7 & 8 & 9 \\
\hline
\end{tabular}

31. To what extent does your comfort level with computers facilitate participation in online teaching?

\begin{tabular}{lcccccccc} 
Nothing & \multicolumn{3}{c}{ Very Little } & Some & & Quite a Bit & A Great Deal \\
\hline 1 & 2 & 3 & 4 & 5 & 6 & 7 & 8 & 9 \\
\hline
\end{tabular}

32. How well can you navigate the internet to provide links and resources to students in an online course?

\begin{tabular}{lcccccccc} 
Nothing & \multicolumn{2}{c}{ Very Little } & Some & & Quite a Bit & A Great Deal \\
\hline 1 & 2 & 3 & 4 & 5 & 6 & 7 & 8 & 9 \\
\hline
\end{tabular}




\section{Directions for Scoring the Educators' Sense of Online Teaching Efficacy Scale (Questions 1-32)}

Scoring: Responses vary along a nine-point scale defined by the categories "Nothing", "Very little", "Some Influence", "Quite A Bit" and "A Great Deal." (1 though 9 respectively). The higher the cumulative score on the scale, the greater sense of efficacy for that aspect of online teaching. Calculate the means of the subscales and add these means to find an overall online teaching efficacy score between 4 through 36 . Higher scores indicate greater overall teachers' sense of efficacy for online teaching.

Subscale Scores: To determine the Efficacy in Online Student Engagement, Efficacy in Online Instructional Practices, Efficacy in Online Classroom Management and Efficacy in Use of Computers subscale scores:

\section{Efficacy in Student Engagement:}

Add Score from items: $1+2+4+6+9+12+14+22=$ Total Score is divided by 8 to get the mean score.

\section{Efficacy in Instructional Strategies:}

Add Score from items: $7+10+11+17+18+20+23+24=$ Total Score is divided by 8 to get the mean score.

\section{Efficacy in Classroom Management:}

Add Score from items: $3+5+8+13+15+16+19+21=$ Total Score is divided by 8 to get the mean score.

\section{Efficacy in Use of Computers:}

Add Score from items: $25+26+27+28+29+30+31+32=$ Total Score is divided by 8 to get the mean score. 